\title{
PSYCHOLOGY
}

\section{EMOTIONAL BURNOUT AS A MODERATOR OF TV NEWS IMPACT ON YOUNG ADULT AUDIENCE: EEG STUDY}

Volodymyr Rizun, doctor of science, phd in journalism, institute of journalism

Yurii Havrylets, phd in journalism, institute of journalism

Sergii Tukaiev, phd in biology, institute of journalism

Maksym Khylko, phd in politics, institute of journalism

Anatolii Vasilchenko, master in neurophysiology, institute of biology and medicine

Taras Shevchenko National University of Kyiv

DOI: https://doi.org/ 10.31435/rsglobal_ws/30112018/6237

\section{ARTICLE INFO}

Received: 19 September 2018

Accepted: 24 November 2018

Published: 30 November 2018

\section{KEYWORDS}

TV,

EEG,

Brain Load Index, emotional burnout.

\begin{abstract}
The paper considers changes of the EEG parameters while viewing the emotionally accented TV messages depending the emotional burnout formation. We found that the character and degree of EEG changes during the perception of emotional stimuli significantly depend on the characteristics of a particular stimulus and the current level of emotional state of the viewers (emotional burnout, fatigue). The subjects with the phase of resistance of the emotional burnout syndrome at the stage of formation ("Burnout RP under development") differ significantly from the groups with the unformed and formed Burnout Resistance Phase ("Burnout RP unformed", "Burnout RP formed") in the dynamics of changes of spectral power of the EEG subbands during the exposure to the emotional stimuli. The development of burnout is characterized by an increase in State Anxiety and fatigue, the desensitization to the emotionally accented information, an augmentation in social alienation and, eventually, manifests in changes in the brain response to emotional stimuli, which consist in the inhibition of high-frequency EEG components.
\end{abstract}

Citation: Volodymyr Rizun, Yurii Havrylets, Sergii Tukaiev, Maksym Khylko, Anatolii Vasilchenko. (2018) Emotional Burnout as a Moderator of TV News Impact on Young Adult Audience: Eeg Study. World Science. 11(39).doi: 10.31435/rsglobal_ws/30112018/6237

Copyright: (C) 2018 Volodymyr Rizun, Yurii Havrylets, Sergii Tukaiev, Maksym Khylko, Anatolii Vasilchenko. This is an open-access article distributed under the terms of the Creative Commons Attribution License (CC BY). The use, distribution or reproduction in other forums is permitted, provided the original author(s) or licensor are credited and that the original publication in this journal is cited, in accordance with accepted academic practice. No use, distribution or reproduction is permitted which does not comply with these terms.

Introduction. TV, especially the TV news, focuses primarily on the negative aspects of life [Johnson, 1996]. More than half of the TV news plots depict violence, suffering, war, and street unrest [Johnson, 1996]. It is known that negative video has an effect on the physiological state of a person comparable to the painful affect of the corresponding negative situations in real life on the person [Bower, 1983; Newhagen, 1998]. The magnitude of cognitive and neuronal responses to images with scared faces is positively associated with fear and anxiety [Rauch et al, 2000; van Honk et al, 2002; Fox et al, 2005; Putman et al, 2010]. This indicates that the viewing of scenes with negative events causes physiological changes that are characteristic to the experiencing negative events. The reaction to the watching such TV news is accompanied by an increase in the level of fear and anxiety. 
Earlier a relation between television viewing and stress was found [Propper et al, 2007]. Heavy TV viewing leads to cognitive overload and stress development [Lang et al, 1995; 1999]. The frequency of TV viewing is positively associated with post-traumatic stress disorder (PTSD) among the victims of catastrophes [Ahern et al, 2002]. Prolonged exposure to stress while viewing negative, violent TV programs can lead to the development of burnout syndrome, as the form of the cumulative stress. This phenomenon is accompanied by the gradual emergence of changes in the psychoemotional sphere of a person. It is not known how these changes affect the perception of emotionally negative TV news. Although the currently available data indicate that such changes must be in accordance with the overall picture of violations of a person's emotional domain. It is also unknown how the perception of positive TV news stories changes in this condition and how the cortical activity differ while viewing the positive and negative TV messages in a state of stress.

TV viewing (news program, commercials) affects the EEG parameters of the cortical activity. It was showed that the spectral power of the $\alpha$-band in posterior area negatively correlates with the frequency of scene changes. The same relationship was shown for the spectral power of the lower $\alpha$ subband and the subjective interest of the viewer [Smith \& Gevins, 2004]. Desynchronization of the alpha band in the parietal area while watching TV messages reflects a high level of emotional arousal and greater attention to the stimuli [Simons et al, 2003]. Memorization index of the content of commercials inversely correlates with the power of the upper $\alpha$-subband in the frontal cortex. The $\alpha 2$ - and $\beta 1$-subbands are sensitive to the verbal and visual affective cues of the news videos [Schellberg et al, 1990]. Differences in the $\gamma$-band in the orbitofrontal cortex while viewing emotional and non-emotional advertising messages are the criterion of engagement of viewers, the reward value of the stimuli [Babiloni et al, 2006]. There is a large activation in the left hemisphere during the watching positive plots and a greater activation in the right hemisphere while viewing the stimuli with a negative valence [Reeves et al, 1989]. In general, activation in the frontal and occipital areas on the negative stimuli is greater than on the positive ones, but the interhemispheric asymmetry observed only in the anterior area. It indicates that both hemispheres process information in parallel.

It was detected a greater $\theta$-activation in the frontal regions, $\alpha$-activation in the left hemisphere and the right orbitofrontal cortex and a larger bilateral activation in the $\gamma$-range in the prefrontal and orbitofrontal cortex while viewing the pleased TV stories. At the same time, negative attitudes towards TV messages are reflected in the activation in the left prefrontal cortex in the $\beta$-range [Vecchiato et al, $2009 ; 2010]$. Memorization of the TV commercials is accompanied by an increase in $\theta$ - and $\beta$-activity in the left frontal and prefrontal areas, $\gamma$-activity in the prefrontal and frontal areas of both hemispheres and depression of $\alpha$-band in the left hemisphere. For forgotten videos, $\alpha$-activation in the front-central and right prefrontal areas and $\beta$-activation in the right hemisphere are typical [Vecchiato et al, 2009; 2010]. It is accepted that the left prefrontal and frontal cortex is involved in the transfer of sensory traces from short-term to long-term memory [Tulving et al, 1994], which may explain the large activation in these areas when viewing the remembered videos. Watching the remembered commercials causes a longer depression of $\alpha$-activity and a longer period of dominance of the left hemisphere. Viewing the forgotten advertising messages leads to a rapid but short-term fall in $\alpha$ activity and a long dominance of the right hemisphere [Rothschild \& Hyun, 1990].

Thus, watching TV news affects the EEG parameters. The nature of these changes depends on the features of the video such as emotional valence.

In the previous study we showed that the impact of negative TV news depends on the viewers' burnout [Havrylets et al, 2018]. The emotional burnout is a result of the prolonged action of moderateintensity job stress. Burnout consists of a process of gradual loss of emotional, cognitive and physical energy, which is manifested in the symptoms of emotional, mental exhaustion, physical fatigue, personal estrangement, depersonalization and reduction of pleasure from the done work [Maslach, 2006]. Inadequate selective emotional response is characterized by a violation of the perception of the difference between emotional stimuli and retrenchment in expressions of emotion. The intensity of social interactions and the proportion of the emotional component in them decrease. The reduction in the ability of emotional interactions leads to the fact that they become selective: the intensity of emotions decreases, as well as the range of situations in which a person resorts to emotional interactions, a person begins to show emotional reactions only when she has enough resources for it [Vodopyanova \& Starchenkova, 2009].

Recent studies show that emotional burnout is characterized not only by cognitive and emotional changes, but also physiological ones. Emotional burnout is characterized by the changes in the biochemical properties of the brain. Chronic stress leads to the decrease binding potential for 5-HT $1 \mathrm{~A}$ receptors in the limbic system [Blix et al, 2013]. In the end the development of the burnout 
changes the brain morphologically. People experiencing prolonged stress demonstrate a significant reduction in the gray matter volume of the anterior cingulate cortex and the dorsolateral prefrontal cortex [Blix et al, 2013]. The volume of the caudate nucleus and putamenis inversely correlated with the level of stress [Blix et al, 2013]. Emotional burnout affects the electrophysiological parameters of the human brain. It has been shown that burnout patients have the decreased amplitude of the P300 in response to audio stimuli, the lower dominant frequency of the $\alpha$-band and the spectral power of the $\beta$ band than control subjects. [Van Luijtelaar et al, 2010]. The study of Tukaiev et al. [2012] pointed out the different EEG characteristics in men and women during the formation of burnout. Women's reaction to burnout includes the reduction of the amount of interhemispheric coherence in lowfrequency EEG components, while man's reaction-decrease of them in middle and high-frequency EEG components.

Purpose of the study. The purpose of research is to reveal the influence of TV news on psycho-emotional state of youth audience, the extent to which emotional burnout determines the perception of emotional stimuli.

Sample. 91 healthy volunteers (62 women and 29 men) aged 18 to 26 years $\left(M_{\text {age }}=19.47, S D=1.67\right.$ years) participated in the EEG study. The participants were eligible to enroll in the study if they had normal or corrected-to-normal visual acuity, normal color vision, had no clinical manifestations of mental or cognitive impairment, verbal or non-verbal learning disabilities. Written informed consent was obtained from each subject in accordance with the Helsinki Declaration; the study was approved by the local ethical committee. All volunteers participated in the study for course credits. They were tested 1-3 months before the exam time (baseline session).

EEG recordings. The EEGs were recorded monopolarly using EEG 23 Ch system Neurocom (Ukraine, XAI-MEDICA). The electrodes (silver/silver chloride) were placed on the scalp at symmetrical anterior frontal (Fp1, Fp2), frontal (F3, F4, Fz, F7, F8), central (C3, C4, Cz) parietal (P3, P4, Pz), occipital (O1, O2) and temporal (T3, T4, T5, T6) recording sites according to the international 10-20 scheme. All electrodes were referenced to the interconnected ear reference electrodes. The interelectrode impedance levels were below $5 \mathrm{k} \Omega$. The sample rate of all channels was $500 \mathrm{~Hz}$. A high-frequency filter with a $30 \mathrm{~Hz}$ cut-off frequency and a power network filter $(50 \mathrm{~Hz})$ were used; the time constant of the amplification tract was $0.3 \mathrm{sec}$.

Stimuli. Selection of the stimuli encompassed several steps in accordance with the principles, described earlier [Havrylets et al, 2016; 2018]. At first, 25 coders (13 women and 12 men, aged 18 to 19 years $\left(M_{a g e}=18.44, S D=0.5\right.$ years $)$ selected experimental stimuli from the pool of $100 \mathrm{TV}$ news stories (only those TV messages created and voiced by journalists; comments of a presenter, as well as reporters' live broadcasts were excluded) and $10 \mathrm{TV}$ ads (food and drink commercials previously shown on TV) using a 10-grade "negative - positive" Likert-type scale (-5 - very negative, 0 - neutral, +5 - very positive). Selected 4 negative TV news reports that had the nearest scores to the group's mean were regarded as typical with scenes of outright violence, as of natural disasters. $10 \mathrm{TV}$ ads were classified the same way and $3 \mathrm{TV}$ commercials demonstrated positive valence (values from +1 to +5 ).

General Procedure of Trial. The participants were seated in a comfortable armchair in a dimly lit recording booth in front of the standard 17" LCD monitor with a distance of $80 \mathrm{~cm}$ away from the computer screen. We recorded EEG using the following protocol. After adaptation to the study condition ( $2 \mathrm{~min}$ ) EEG was registered during the two periods of resting-state EEG, one with eyes closed $(3 \mathrm{~min})$, the other with eyes open $(1 \mathrm{~min})$ and while watching the video set $(7 \mathrm{~min} 38 \mathrm{sec}$ as a whole). Video stimuli were presented on the screen monitor (LG FLATRON L1717S, LCD monitor / TFT active matrix, display diagonal 17", maximum native display resolution 1280x1024 at $75 \mathrm{~Hz}$, refresh rate $60 \mathrm{~Hz}$, display brightness $250 \mathrm{~cd} / \mathrm{m}^{2}$, display contrast ratio 500:1, horizontal refresh rate $83 \mathrm{~Hz}$, vertical refresh rate $75 \mathrm{~Hz}$ ) using the GOM Player 2.3.14.5270 (Gretech Online Movie Player) for Windows XP/7/8/10 that is the most advanced, familiar and used over the world due to playing numerous multimedia formats. Sounds with an intensity of about $70-85 \mathrm{~dB}$ were played from a two nearby multimedia Hi-Fi stereo speakers (Genius SP-G06, frequency range $60-20000 \mathrm{~Hz}$ ) and kept constant for all participants.

There were 7 videos with high video and audio quality, 2 blocks of negative TV news interrupted by set of positive TV ads. Between each video we recorded 1.5-min-long EEG segments during observing empty gray colored screen.

Questionnaires. Such tests as Mood self-assessment, State Anxiety Inventory of C. Spielberger, Y. Hanin, Dayhoff Internal Aggression Inventory, and WAM (Well-being, Activity, Mood) were administered before and after the experiment. At the end of the experiment we used Aggression Test by A. Assinger (assessment of aggressiveness in the relationship). 
Before the experiment the participants rated their level of burnout using the Boyko Syndrome of emotional burnout Inventory, adapted for students by Tukaiev and Vasheka [Vasheka \&Tukaiev, 2011; Tukaiev et al, 2013]. The Boyko Inventory consists of three parts that consider variations of the parameters of psychological and emotional activity: Anxiety Tension, Resistance, and Exhaustion [Vodopiyanova \& Starchenkova, 2009]. The value of each of these phases is measured on a scale from 0 to 120 points: 0 to 36 points - the phase is not formed, 37 to 60 points - the phase is under development, 61 to 120 points - the phase is formed.

Data analysis. Statistical processing of the obtained data was performed using the Wilcoxon rank criterion, the Man-Whitney U-test and the Kolmogorov-Smirnov test (StatSoft STATISTICA 64, version 10.0.1011.0). Differences were considered statistically significant if the $\mathrm{p}<0.05$.

Results. To establish electroencephalographic correlates of stress-sensitivity when viewing videos brain load index (BLI) was calculated. This index is defined as the ratio of the spectral power of the midline frontal $\theta$-band $(\mathrm{Fz})$ to the spectral power of the midline posterior $\alpha$-band $(\mathrm{Pz}): \mathrm{BLI}=$ $\theta(\mathrm{Fz}) / \alpha(\mathrm{Pz})$. The ratio of activity in the frontal and posterior regions of the cortex may underlie the valence of the experienced emotion [Giannakakis et al, 2015], relates to the stress condition [Tiinanen et al, 2011]. Also it was shown that the rise in cognitive brain load increases frontal theta activity and decreases parietal alpha activity [Sauseng et al, 2005]. Midline frontal theta activity reflects focused attentional processing [Ishii et al, 1999], cognitive control [Cavanagh \& Frank, 2014], ongoing topdown preparation for the performance of subsequent tasks [Min, \& Park, 2010], is involved in active memory maintenance and recall of working memory representations [Jensen \& Tesche, 2002]. Synchronization of theta and alpha lower synchronization correlate with emotionally positive state and internalized attention [Aftanas \& Golocheikine, 2001]. Cortical alpha rhythms may indirectly modulate by the anterior and medial dorsal nuclei (the ascending neuromodulatory system), that affect vigilance, and arousal levels by this way [Liu et al, 2012].

Therefore, in view of the purpose of our study, it was appropriate to assess the difference in the changes in the BLI while viewing emotional videos between groups with different levels of emotional burnout. According to the results of the Boyko Syndrome of emotional burnout inventory, the participants were divided into three groups: the phase of resistance unformed, under development, and formed.

In the group with the unformed phase of Resistance, the BLI increase was observed while viewing the second and fourth TV news stories $(68.17 \%(\mathrm{p}=0,001)$ and $29.84 \%(\mathrm{p}=0,02)$ respectively) and the first and second advertisings $(28.98 \%(\mathrm{p}=0,008)$ and $35.44 \%(\mathrm{p}=0,009)$ respectively) (Figure 1). In the group with the Resistance phase under development, a BLI rise during watching the second and third negative videos $(15.99 \%, \mathrm{p}=0.002$ and $15.43 \%, \mathrm{p}=0.04)$ and all advertising messages $(27.76 \%(\mathrm{p}=0.002), 21.2 \%(\mathrm{p}=0.01)$ and $26.61 \%(\mathrm{p}=0.02)$ respectively) (Figure 2 ). The increase in BLI was detected in the group with the formed Resistance stage while viewing the first and fourth negative TV news stories $(20.98 \%, \mathrm{p}=0.04$ and $26.7 \%, \mathrm{p}=0.02)$ and the first and third positive TV news stories $(36.19 \%, \mathrm{p}=0.007$ and $34.45 \%, \mathrm{p}=0.04)$ (Figure 3 ).

To assess the differences of the BLI between groups with different levels of burnout the ManWhitney U-test was performed. Significant differences in the BLI values while viewing TV messages between groups were not found.

The observed increase in the theta Fz/alpha Pz ratio reflects an enhancement of the activation level, amount of brain resources involved in processing the perceived information. Our findings reflect the level of subjects' involvement in the process of experiencing emotional events on the TV screen depending on the emotional burnout formation level. The group with the phase of resistance unformed responded to a negative video with more force than on a neutral stimulus. Subjects with the phase of resistance formed react mostly on the transition from one emotional valence on the opposite one.

We argue that emotional burnout affects attention, amount of brain resources used to analyze events transmitted on TV screen. As regards the emotional involvement of the participants it is also determined by their emotional state. 


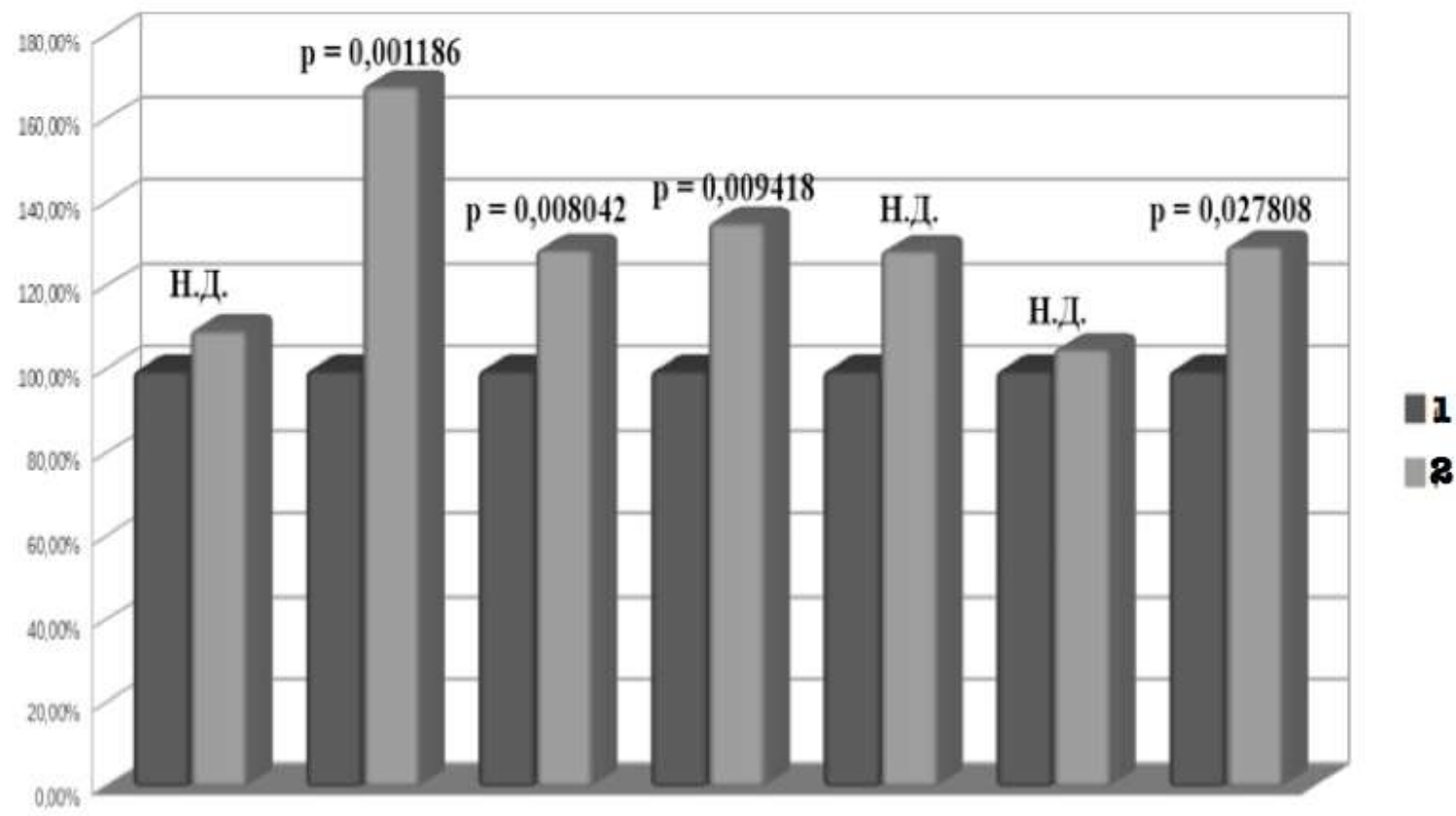

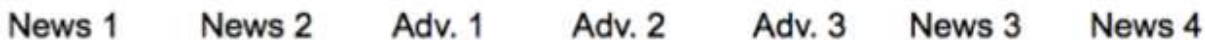

Fig. 1. BLI while viewing negative TV news and positive TV commercials in a group with the phase of resistance unformed. (1) - rest state, (2) watching video.

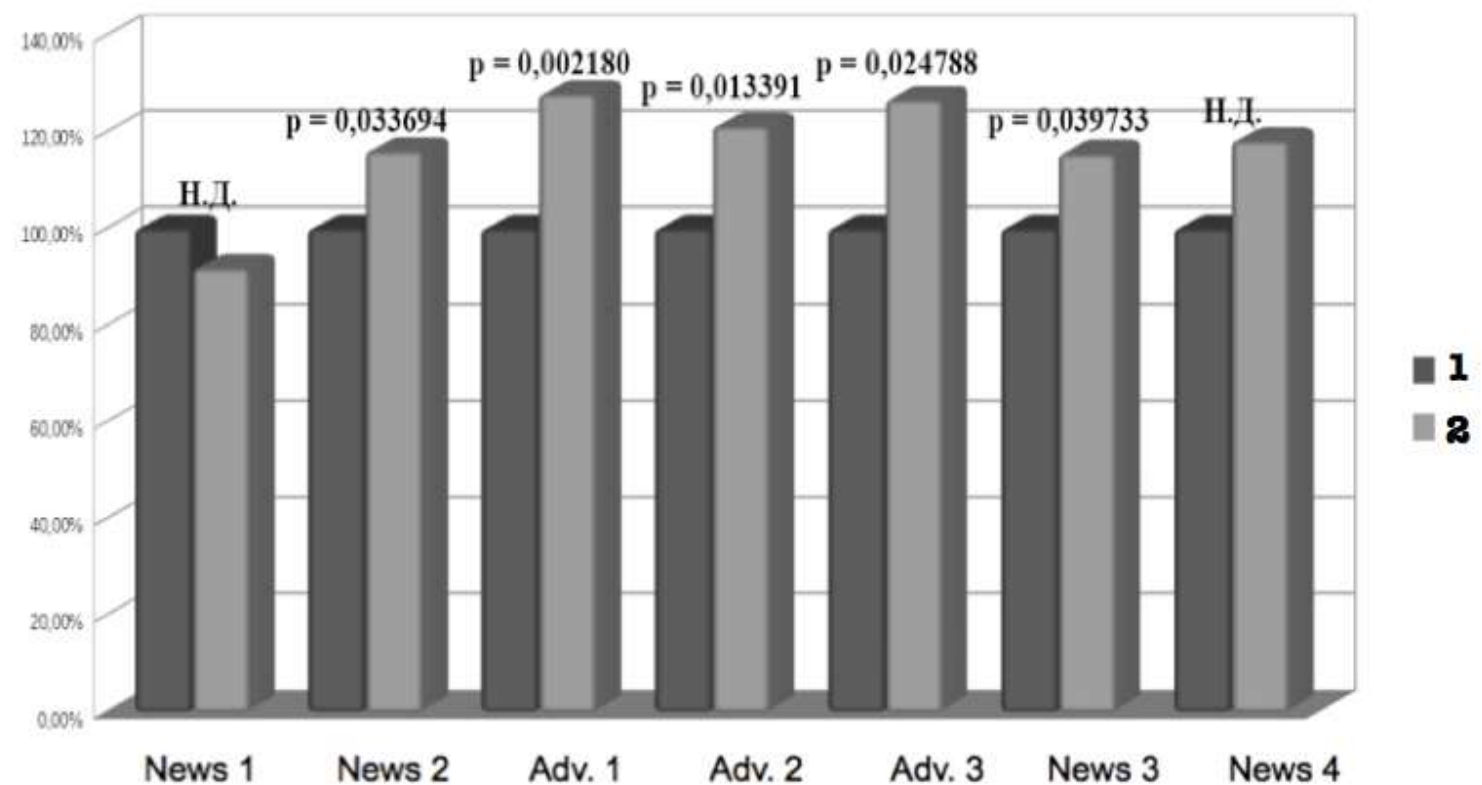

Fig. 2. BLI while viewing negative TV news and positive TV commercials in a group with the phase of resistance under development. (1) - rest state, (2) watching video. 


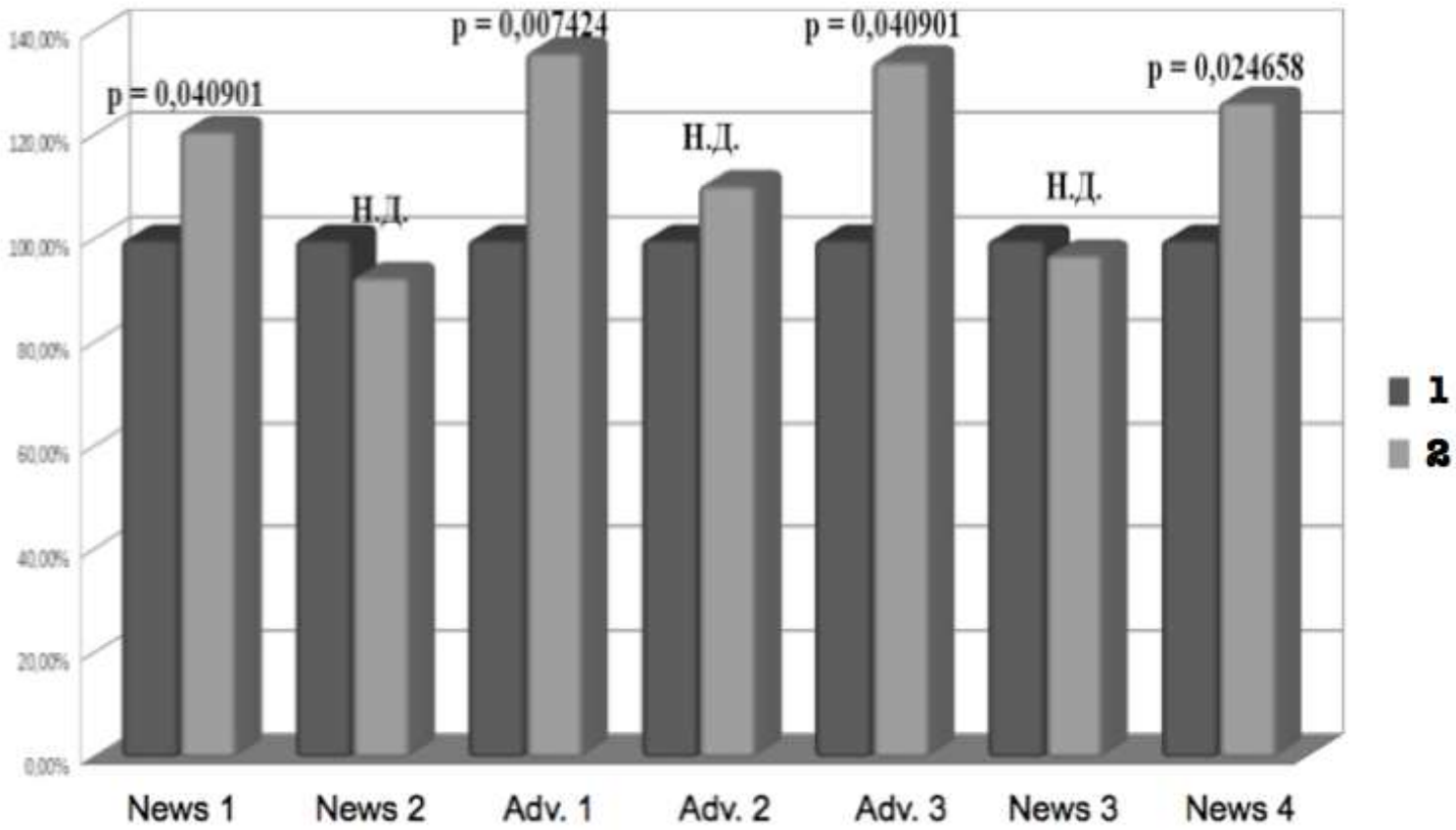

Fig. 3. BLI while viewing negative TV news and positive TV commercials in a group with the phase of resistance formed. (1) - rest state, (2) watching video.

Competing interests. The authors declare that they have no competing interests.

\section{REFERENCES}

1 Aftanas, L. I., \& Golocheikine, S. A. (2001). Human anterior and frontal midline theta and lower alpha reflect emotionally positive state and internalized attention: high-resolution EEG investigation of meditation. Neuroscience letters, 310(1), 57-60.

2 Ahern, J., Galea, S., Resnick, H., Kilpatrick, D., Bucuvalas, M., Gold, J., \&Vlahov, D. (2002). Television images and psychological symptoms after the September 11 terrorist attacks. Psychiatry: Interpersonal and Biological Processes, 65(4), 289-300.

3 Babiloni, F., Cincotti, F., Mattia, D., Mattiocco, M., Bufalari, S., Fallani, F. D. V., ... \&Astolfi, L. (2006, August). Neural basis for the brain responses to the marketing messages: an high resolution EEG study. In Engineering in Medicine and Biology Society, 2006.EMBS'06.28th Annual International Conference of the IEEE (pp. 3676-3679). IEEE.

4 Blix, E., Perski, A., Berglund, H., \&Savic, I. (2013). Long-term occupational stress is associated with regional reductions in brain tissue volumes. PLoS One, 8(6), e64065.

5 Bower, G. H. (1983). Affect and cognition. Phil. Trans. R. Soc. Lond. B, 302(1110), 387-402.

6 Cavanagh, J. F., \& Frank, M. J. (2014). Frontal theta as a mechanism for cognitive control. Trends in cognitive sciences, 18(8), 414-421.

7 Fox, E., Russo, R., \& Georgiou, G. A. (2005). Anxiety modulates the degree of attentive resources required to process emotional faces. Cognitive, Affective, \& Behavioral Neuroscience, 5(4), 396-404.

8 Giannakakis, G., Grigoriadis, D., \&Tsiknakis, M. (2015, August). Detection of stress/anxiety state from EEG features during video watching. In Engineering in Medicine and Biology Society (EMBC), 2015 37th Annual International Conference of the IEEE (pp. 6034-6037). IEEE.

9 Havrylets, Y., Rizun, V., Tukaiev, S., \&Khylko, M. (2016). Objectification of Subjectivity: International Experience in Selection of TV Stimuli in Mass Media Effect Research.Current Issues of Mass Communication, 19, 8-20.

10 Havrylets, Y. D., Tukaiev, S. V., Rizun, V. V., \&Khylko, M. M. (2018). State Anxiety, Mood, and Emotional Effects of Negative TV News Depend on Burnout. Medijskestudije (Media Studies), 9 (18) (in press)

11 Ishii, R., Shinosaki, K., Ukai, S., Inouye, T., Ishihara, T., Yoshimine, T., ... \& Takeda, M. (1999). Medial prefrontal cortex generates frontal midline theta rhythm. Neuroreport, 10(4), 675-679.

12 Jensen, O., \&Tesche, C. D. (2002). Frontal theta activity in humans increases with memory load in a working memory task. European journal of Neuroscience, 15(8), 1395-1399.

13 Johnson, R. N. (1996). Bad news revisited: The portrayal of violence, conflict, and suffering on television news. Peace and Conflict, 2(3), 201-216. 
14 Lang, A., Dhillon, K., \& Dong, Q. (1995). The effects of emotional arousal and valence on television viewers' cognitive capacity and memory. Journal of Broadcasting \& Electronic Media, 39(3), 313-327.

15 Lang, A., Bolls, P., Potter, R. F., \& Kawahara, K. (1999). The effects of production pacing and arousing content on the information processing of television messages. Journal of Broadcasting \& Electronic Media, 43(4), 451-475.

16 Liu, Z., de Zwart, J. A., Yao, B., van Gelderen, P., Kuo, L. W., \&Duyn, J. H. (2012). Finding thalamic BOLD correlates to posterior alpha EEG. Neuroimage, 63(3), 1060-1069.

17 Maslach, C. (2006). Understanding job burnout. In A. M. Rossi, P. Perrewe, and S. MaslachSauter (Eds.), Stress and quality of working life: Current perspectives in occupational health (pp. 37-51). Greenwich, CT: Information Age Publishing.

18 Min, B. K., \& Park, H. J. (2010). Task-related modulation of anterior theta and posterior alpha EEG reflects top-down preparation. BMC neuroscience, 11(1), 79.

19 Newhagen, J. E. (1998). TV news images that induce anger, fear, and disgust: Effects on approachavoidance and memory. Journal of Broadcasting \& Electronic Media, 42(2), 265-276.

20 Propper, R. E., Stickgold, R., Keeley, R., \&Christman, S. D. (2007). Is television traumatic?: Dreams, stress, and media exposure in the aftermath of September 11, 2001. Psychological Science, 18(4), 334-340.

21 Putman, P., van Peer, J., Maimari, I., \& van der Werff, S. (2010). EEG theta/beta ratio in relation to fearmodulated response-inhibition, attentional control, and affective traits. Biological psychology, 83(2), 73-78.

22 Rauch, S. L., Whalen, P. J., Shin, L. M., McInerney, S. C., Macklin, M. L., Lasko, N. B., ... \& Pitman, R. K. (2000). Exaggerated amygdala response to masked facial stimuli in posttraumatic stress disorder: a functional MRI study. Biological psychiatry, 47(9), 769-776.

23 Reeves, B., Lang, A., Thorson, E., \& Rothschild, M. (1989).Emotional television scenes and hemispheric specialization. Human Communication Research, 15(4), 493-508.

24 Rothschild, M. L., \& Hyun, Y. J. (1990). Predicting memory for components of TV commercials from EEG. Journal of consumer research, 16(4), 472-478.

25 Sauseng, P., Klimesch, W., Schabus, M., \&Doppelmayr, M. (2005).Fronto-parietal EEG coherence in theta and upper alpha reflect central executive functions of working memory. International Journal of Psychophysiology, 57(2), 97-103.

26 Schellberg, D., Besthorn, C., Klos, T., \& Gasser, T. (1990). EEG power and coherence while male adults watch emotional video films. International Journal of Psychophysiology, 9(3), 279-291.

27 Simons, R. F., Detenber, B. H., Cuthbert, B. N., Schwartz, D. D., \& Reiss, J. E. (2003). Attention to television: Alpha power and its relationship to image motion and emotional content. Media psychology, 5(3), 283-301.

28 Smith, M. E., \&Gevins, A. (2004). Attention and brain activity while watching television: Components of viewer engagement. Media Psychology, 6(3), 285-305.

29 Tiinanen, S., Mättä, A., Silfverhuth, M., Suominen, K., Jansson-Verkasalo, E., \&Seppänen, T. (2011, August). HRV and EEG based indicators of stress in children with Asperger syndrome in audio-visual stimulus test. In Engineering in Medicine and Biology Society, EMBC, 2011 Annual International Conference of the IEEE (pp. 2021-2024). IEEE.

30 Tukaiev, S., Krizhanovskiy, S., Zima, I., Filimonova, N., Radchuk, O., Cherninskiy, A., \&Zalevska, O. (2012). Gender-related differences in spatial synchronization in EEG in burnout students.Psychophysiology. 49(Suppl. 1), S120-S120.

31 Tukaiev, S. V., Vasheka, T. V., \&Zyma, I. G. (2013). [Psychological and neurophysiological aspects of the emotional burnout development].In V. P. Volkoff (Ed.), Actual aspects of internal medicine (86-107). Novosibirsk: SibAK

32 Tulving, E., Kapur, S., Craik, F. I., Moscovitch, M., \&Houle, S. (1994). Hemispheric encoding/retrieval asymmetry in episodic memory: positron emission tomography findings. Proceedings of the National Academy of Sciences, 91(6), 2016-2020.

33 van Honk, J., Schutter, D. J., d'Alfonso, A. A., Kessels, R. P., \& de Haan, E. H. (2002). 1 hzrTMS over the right prefrontal cortex reduces vigilant attention to unmasked but not to masked fearful faces. Biological psychiatry, 52(4), 312-317.

34 van Luijtelaar, G. V., Verbraak, M., Bunt, M. V. D., Keijsers, G., \&Arns, M. (2010). EEG findings in burnout patients. The Journal of Neuropsychiatry and Clinical Neurosciences, 22(2), 208-217.

35 Vasheka, T. V., \&Tukaiev, S. V. (2011). [Determinants of emotional burnout of students studying psychology in learning]. Problems of General and Educational Psychology.XIII(6): 47-55.

36 Vecchiato, G., Astolfi, L., Fallani, F. D. V., Salinari, S., Cincotti, F., Aloise, F., ... \&Babiloni, F. (2009, September). The study of brain activity during the observation of commercial advertsing by using high resolution EEG techniques. In Engineering in medicine and biology society, 2009. embc 2009. annual international conference of the ieee (pp. 57-60). IEEE.

37 Vecchiato, G., Astolfi, L., Fallani, F. D. V., Cincotti, F., Mattia, D., Salinari, S., ... \&Babiloni, F. (2010). Changes in brain activity during the observation of TV commercials by using EEG, GSR and HR measurements. Brain topography, 23(2), 165-179.

38 Vodopyanova, N, \&Starchenkova, E. (2009) Syndrome of Burnout: Diagnostics and Prevention. Saint Petersburg: Piter. 